\title{
MIEDO A LA ARQUITECTURA
}

Francisco Díaz

Profesor, Pontificia Universidad Católica de Chile
$\mathbf{P}$ ara varias generaciones de arquitectos chilenos, el terremoto del 27 de febrero de 2010 fue su primera experiencia en una catástrofe. Preparados para inventar y desarrollar productos para el futuro, este desastre ha obligado a ponerse en la posición de analistas del pasado. No se ha tratado de una exploración histórica o hermenéutica, ni tampoco de un análisis de oportunidades; se trató, más bien, de un estudio científico, en el cual los productos de la arquitectura -sus construcciones- debían ser examinados en forma precisa, para evaluar el grado de seguridad que proveían tras el terremoto.

La destrucción de las construcciones a causa del sismo no solo reveló la vulnerable realidad material de gran parte de Chile; también que aquella capa invisible que separa lo íntimo y lo público -y que habitualmente conocemos como pudor- estaba íntimamente relacionada con dos opuestos que la arquitectura es capaz de generar: seguridad y miedo. Ante ellos y la emergencia de la catástrofe, sin haber necesariamente ensayado, los arquitectos debimos asumir un papel radicalmente distinto y difícil de interpretar.

PUDOR

Se supone que las construcciones están ahí para proteger algo. Pueden proteger bienes, resguardar de las variaciones del clima o confinar una cantidad medida de espacio donde se desarrolla un guión específico: su uso. Un "cofre de la vida" en palabras de Le Corbusier, que además resguarda esa instancia difícil de medir, pero simple de asumir: la privacidad y la intimidad.

¿Qué sería de un hospital donde la enfermedad estuviese a la intemperie o de un baño en que la relación con el propio cuerpo quedase expuesta? Si bien en ciertos momentos la arquitectura ha jugado a manipular esas condiciones ${ }^{1}$, el resguardo de la privacidad y la intimidad ha resultado prioritario y esos casos han quedado relegados a la categoría de experimentos culturales.

La arquitectura, entendida en su dimensión de hecho construido, desarrolla su potencial en la confinación de esos espacios donde los distintos usos tienen un lugar y resguarda su privacidad. En ese sentido y en su dimensión más primaria, una casa sería el lugar inicial de resguardo de la intimidad y sus subdivisiones internas la evidencia de las privacidades individuales que cobija.

El doble juego de privacidad y exposición con que opera la arquitectura se manifiesta de forma evidente en la diferencia entre la elevación externa de una construcción -o la cara que muestra al público- y las "decoraciones" que los habitantes realizan en las fachadas interiores de sus espacios. En esta última dimensión es donde aparecen con mayor fuerza las preferencias más íntimas, aquellas que existen, pero que no se muestran a la calle: muebles, adornos, cuadros y algún póster, entre otros.

Ese carácter de la vivienda explica, por ejemplo, la sorpresa que ge-

neró en su momento el artista estadounidense Gordon Matta-Clark con Bingo, cuando desmontó los muros exteriores de una casa suburba$\mathrm{na}^{2}$ y dejó expuesto su interior como fachada. En defensa también de aquella dimensión íntima se entienden las protestas realizadas por los vecinos de la obra House de Rachel Whiteread ${ }^{3}$. En ella, la artista inglesa petrificó con hormigón el interior de una casa en Londres y usó los muros exteriores como encofrado; luego de retirarlos dejó a la vista el negativo del espacio íntimo.

\section{MIEDO}

La catástrofe, sin embargo, invierte esa relación entre publicidad e intimidad. En las ciudades azotadas por el terremoto del 27 de febrero de 2010 se pudieron apreciar muchas casas con su fachada desmontada -como Bingo-, que permitían ver un sinnúmero de intimidades anónimas. Asimismo, en el caso de aquellas que todavía mantenían sus fachadas, los arquitectos accedieron sin problemas a miles de reductos de intimidad.

El miedo que genera un evento catastrófico revierte el cuidado del espacio íntimo, de la misma forma en que la enfermedad inhibe el pudor del enfermo y le permite al doctor operar sobre él. Un terremoto transforma a la arquitectura en "enferma". En ese momento, las construcciones -que originalmente estaban destinadas a proteger- se transforman en potencial amenaza para los cuerpos; con cualquier réplica un muro puede convertirse en un proyectil y quitar justamente aquello que debía proteger: la vida ${ }^{4}$. En esa tensa situación de miedo por lo vivido e incertidumbre por lo que pueda suceder, el arquitecto alcanza un estatus que posee en contadas ocasiones: el de experto.

Muchas veces hemos escuchado que la palabra del arquitecto no tiene la misma validez que la del médico; que una persona no duda de las indicaciones del segundo, pero sí puede poner en duda las recomendaciones del primero. Tal vez eso se deba a que se acude a un arquitecto en situaciones de plenitud y a un médico en instantes de excepción.

1 Un ejemplo de esto es el proyecto Nautilus o la Casa de vidrio de Arturo Torres y Jorge Christie (2000).

2 Se trata de la propiedad situada en el número 349 de Erie Avenue en la ciudad de Niagara Falls, en el estado de Nueva York. En esta casa de dos pisos y muros tinglados Matta Clark trabajó durante diez días de 1974 ejecutando cortes y retiros en la estructura, antes de que se realizara la demolición prevista por las autoridades locales (N. del Ed.)
3 El proyecto se ejecutó en 1993 en una casa victoriana de tres pisos ubicada en el East End de Londres -abandonada y con orden de demolición- y fue desmantelado en 1994.

4 José Ricardo Morales (1969) dice: "La experiencia de la caída en arquitectura se contrapone a la del alzado, en el sentido de que, cuando el edificio se desploma, no es solamente una cosa que se cae, sino que es algo que se cae sobre nosotros y, precisamente, aquello que nos preservaba y aislaba. Por ello, en esas circunstancias ‘se nos viene el mundo encima'”. 

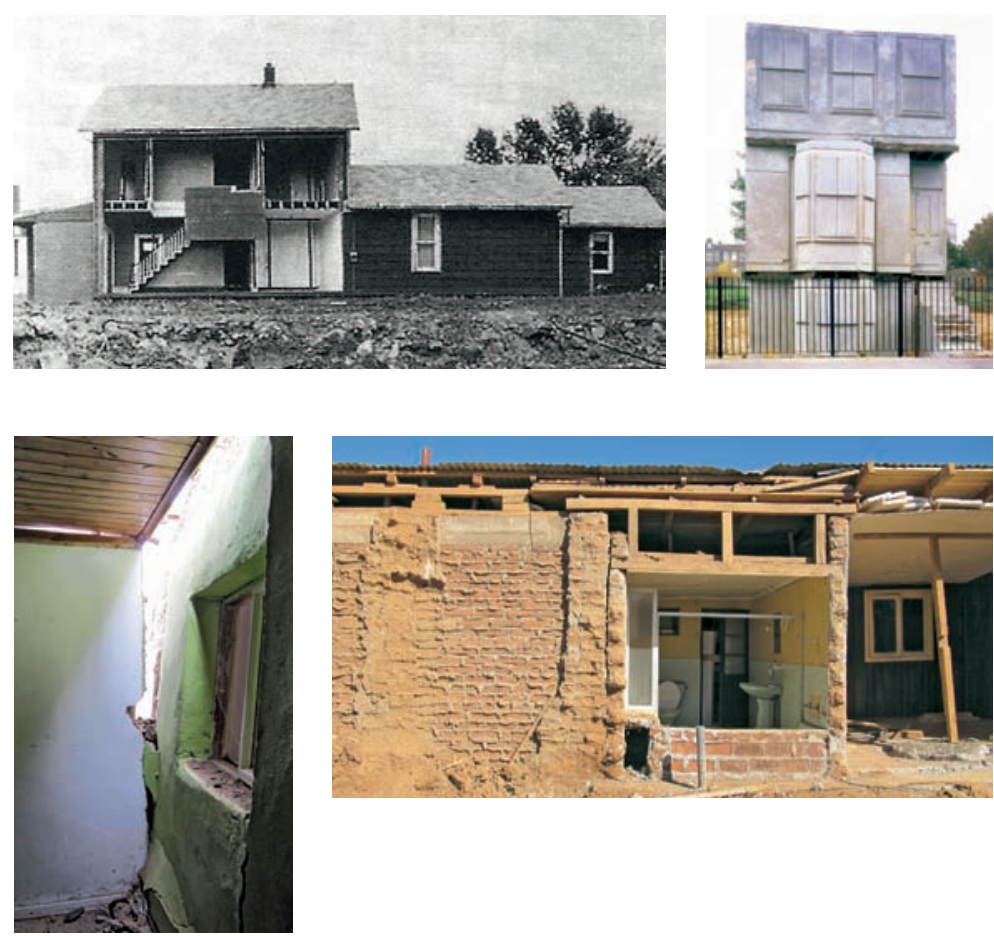

También puede deberse a que el arquitecto opera, como explica Benjamin $^{5}$, como un hechicero cuyas metodologías no son objetivamente comprobables, mientras que el médico opera con procedimientos científicamente establecidos.

Frente a la catástrofe sísmica, la operatividad del arquitecto se focaliza en un aspecto científico: la construcción y su resistencia ante esfuerzos físicos. Este conocimiento técnico aleja al arquitecto de la imprecisa categoría de "artista" y lo acerca al nivel de "experto", cuyo conocimiento puede ser útil para dar seguridad a aquella vida que sus productos -las construcciones- debían resguardar.

Ante este nuevo escenario, determinado por la urgencia de la catástrofe sísmica, las puertas de la intimidad se abren sin pudores al examen del arquitecto. Pero de la misma forma en que un médico toma distancia del cuerpo para poder examinar los síntomas, para responder como arquitectos a la apertura de la intimidad debemos, necesariamente, tomar distancia del apego que sentimos por los edificios.

\section{OPERANDO SIN DOLOR}

En los recorridos de evaluación posterremoto, se podía percibir el nuevo peso que tomaba la voz del arquitecto en este escenario temporal. Personas asustadas abrían su intimidad a cambio de una sugerencia que les diera algo de seguridad, pues confiaban en la palabra de estos expertos.

Si bien es difícil que en el corto plazo vuelva a darse la posibilidad de conocer tantas intimidades diversas en tan corto tiempo, la condición sísmica de nuestro país obliga a no olvidar las -tal vez incómodas- obligaciones que conlleva la condición de experto: actuar, como los médicos, con frialdad y precisión. Frialdad para dejar nuestros pesares de lado y recordar que salvar una construcción no puede ser más importante que salvar una vida; precisión para que nuestro aporte sea útil y responda profesionalmente a la pérdida de pudor de la gente asustada por la catástrofe.

Aunque estemos de acuerdo en que la arquitectura es una disciplina

4 Gordon Matta-Clark. Bingo. Niagara Falls, 1974.Fuente: Moure, Gloria. Gordon Matta-Clark: Obras y escritos. Editorial Polígrafa, Barcelona, 2006.

Rachel Whiteread. House. Londres, 1993. Fuente: Crispiani, Alejandro. "La obra de arte como crítica de arquitectura". ARQ, № 70, Arte y arquitectura. Ediciones $\mathrm{ARQ}$, Santiago, diciembre de 2008.

Curepto, Chile, marzo de 2010.Fotografías del autor.
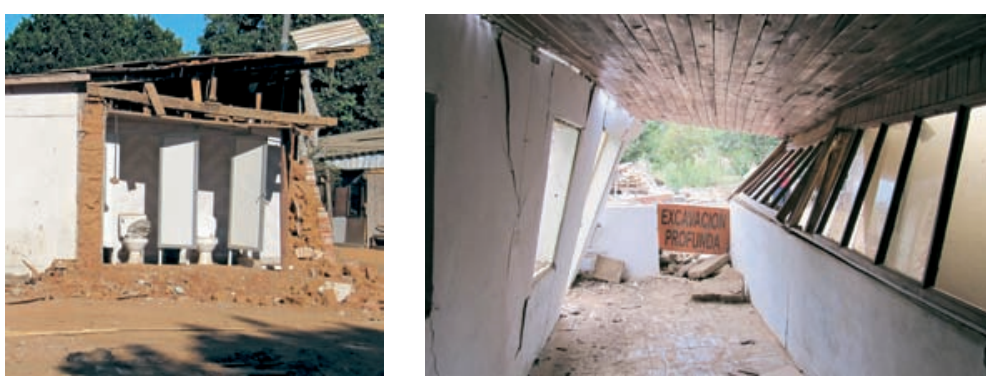

donde no existen las certezas, no podemos pasar por alto que los productos que generamos sí son ciertos, reales y tangibles. Basta un movimiento de la tierra para que ellas dejen de proteger vidas y se transformen en una amenaza y, por lo tanto, si la contingencia nos sitúa en la posición de expertos en el resguardo de la vida, quizás, por ese instante, debemos dejar de pensar como hechiceros y operar, sin dolor, como médicos. ${ }^{6}$ ARQ

5 Benjamin (1989) dice: "A diferencia del hechicero (y siempre hay uno en el médico de cabecera) el cirujano renuncia en el instante decisivo a colocarse frente a su enfermo como hombre frente a hombre; más bien se adentra en él operativamente".

6 Otra mirada a la relación entre arquitectura y medicina es la que plantea Beatriz Colomina en su ensayo Skinless Architecture. En él, Colomina observa que las revoluciones de las metodologías proyectuales en arquitectura han ido siempre de la mano con la aparición de nuevos instrumentos médicos para el análisis del cuerpo humano.

\section{Bibliografía}

BEN JAMIN, Walter. "La obra de arte en la época de su reproductibilidad técnica". Discursos interrumpidos I. Taurus, Buenos Aires, 1989.

CHRISTIE, Jorge y Arturo Torres. "Nautilus, la casa de vidrio". ARO № 46. Ediciones ARQ, Santiago, octubre de 2000, pp. 28-31. COLOMINA, Beatriz. "Soñé que era un muro". En Doble exposición: arquitectura a través del arte. Akal, Madrid, 2006.

COLOMINA, Beatriz. "Skinless Architecture". En Tschumi, Bernard e Irene Cheng (eds.). The State of Architecture at the Beginning of the 21st Century. The Monacelli Press, Columbia Books of Architecture, Nueva York, 2003. MORALES, José Ricardo. Arquitectónica II. Ediciones Universidad de Chile, Santiago, 1969.

MOURE, Gloria. Gordon Matta-Clark: obras y escritos. Editorial Polígrafa, Barcelona, 2006.

Francisco Díaz | Arquitecto y Magíster en Arquitectura, Pontificia Universidad Católica de Chile, 2006. Miembro Fundador de Docoposmo. Autor de la Guía de Arquitectura de Santiago (Buenos Aires, 2008) y co-editor de SCL2110 (Santiago, 2010). Actualmente es docente en la Escuela de Arquitectura de la UC, es parte del equipo de académicos UC a cargo de la reconstrucción patrimonial de Curepto, y arquitecto del Plan de Reconstrucción Sustentable (PRES) para la ciudad de Curicó. 